\title{
FORMAÇÃO CRÍTICA DE PROFESSORES DE LÍNGUA INGLESA: A PÓS-MEMÓRIA COMO RESISTÊNCIA
}

\author{
English Language Teacher Critical Education: \\ Postmemory as Resistance
}

Mariana Adriele COURA

Programa de Pós-Graduação em Estudos Linguísticos

Universidade Federal de Minas Gerais

Conselho Nacional de Desenvolvimento Científico e Tecnológico

anairamcoura@gmail.com

https://orcid.org/0000-0001-8522-2208

Andréa Machado de Almeida MATTOS

Universidade Federal de Minas Gerais

Conselho Nacional de Desenvolvimento Científico e Tecnológico

andreamattos@ufmg.br

https://orcid.org/0000-0003-3190-7329

RESUMO: Neste trabalho focalizaremos especificamente a influência de eventos históricos na formação do professor de línguas a partir do conceito de pós-memória, termo cunhado por Mariane Hirsch para descrever a experiência de uma segunda geração em relação a eventos históricos traumáticos vivenciados pela geração anterior. No Brasil, o Golpe Militar de 1964 e os 20 anos de ditadura que se seguiram ainda impactam todas as áreas da nossa vida, incluindo a educação e o ensino de línguas. Utilizar a memória para ajudar no enfrentamento e na problematização de acontecimentos históricos pode criar espaço para uma educação, incluindo a formação de professores, que tenta evitar os erros do passado e busca construir um futuro melhor. Por meio de geração e análise de dados de cunho qualitativo, relatamos um estudo com professores de língua inglesa atuantes em diversos contextos. Narrativas escritas das experiências dos participantes compõem os dados desta pesquisa. Com base nos resultados, vemos o potencial da pós-memória para promover consciência crítica sobre eventos históricos, fazendo uso das influências sociais, culturais e históricas na formação de professores e problematizando a relação entre histórias de vida, memória e pós-memória como ferramentas para resistência e educação crítica. PALAVRAS-CHAVE: Formação de professores; Pós-memória; Resistência

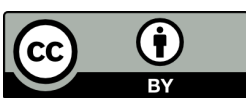




\begin{abstract}
In this paper, we will specifically focus on the influence of historical events in the education of language teachers steming from the concept of postmemory, a term coined by Mariane Hirsch to describe the experience of the second generation in relation do historical traumatic events lived by the previous generation. In Brazil, the 1964 Military Coup and the following 20 years of dictatorship still impact all areas of our lives, including education and language teaching. Using memory to help confront and problematize historical events may create space for an education, including teacher education, which tries to avoid the mistakes of the past and seeks to build a better future. Through the generation and analysis of qualitative data, we report on a study with English language teachers working in different contexts. Written narratives of the participants' experiences constitute the data for this research. Based on the results, we see the potential of postmemory to promote critical awareness of historical events, making use of social, cultural and historical influences in teacher education and problematizing the relationship between life histories, memory and postmemory as tools for resistance and critical education.
\end{abstract} KEY WORDS: Teacher education; Postmemory; Resistance

\title{
INTRODUÇÃO
}

Este artigo $^{1}$ tem como objetivo discutir questões críticas atuais da formação de professores de línguas que têm influenciado as perspectivas sobre letramento e pesquisa no Brasil. Focaremos especificamente na influência de acontecimentos históricos na formação do professor de línguas a partir do conceito de pós-memória, que, segundo Hirsch (1997, p. 22), "caracteriza a experiência daqueles que crescem dominados por narrativas que antecederam seu nascimento, [...] moldadas por eventos traumáticos que não podem ser compreendidos nem recriados".

Hirsch $(1997 ; 2008)$ discute os conceitos de memória e pós-memória em relação ao Holocausto. No contexto brasileiro, o Golpe Militar de 1964, que desencadeou mais de 20 anos de ditadura, ainda impacta todas as áreas de nossas vidas, incluindo a educação

\footnotetext{
${ }^{1}$ A pesquisa que deu origem a este trabalho recebeu financiamento parcial do Conselho Nacional de Desenvolvimento Científico e Tecnológico $(\mathrm{CNPq})$ à primeira autora como Bolsista de Iniciação Científica (PIBIC) e à segunda autora como Bolsista de Produtividade em PesquisaNível 2 (Processo n. 312405/2017-0). As duas autoras deste texto são pesquisadoras do NECLLE - Núcleo de Estudos Críticos sobre Letramentos, Linguagens e Educação, um grupo registrado no CNPq. Este artigo é uma tradução revisada e ampliada de Mattos e Coura (2021a).
} 
e o ensino de línguas. Compreendemos toda a complexidade da situação, no entanto, acreditamos que recorrer à memória para ajudar no enfrentamento e na problematização dos acontecimentos históricos pode criar espaço para um tipo de educação, incluindo a formação de professores de línguas, que tenta evitar os erros do passado e visa a construir um futuro melhor para todos.

Utilizando o paradigma qualitativo para a geração e a análise de dados, desenvolvemos um estudo com professores de línguas em serviço, atuantes em diferentes contextos e matriculados em um curso de pós-graduação em Linguística Aplicada em uma grande universidade federal brasileira. Os dados foram gerados por meio de narrativas escritas sobre as experiências dos participantes. Com base nos resultados, olhamos para o potencial da pós-memória para promover a consciência crítica quanto a discursos turbulentos, fazendo uso de influências sociais, culturais e históricas na formação de professores no Brasil e problematizando a relação entre histórias de vida, memória e pósmemória como ferramentas para a resistência e a educação crítica.

\section{"VIRADAS" NA LINGUÍSTICA APLICADA E NA FORMAÇÃO DE PRO- FESSORES}

Segundo Pennycook (2001), a área de Linguística Aplicada é, por natureza, inter/ transdisciplinar. $\mathrm{O}$ autor, que é um dos mais importantes estudiosos da pesquisa em Linguística Aplicada em todo o mundo, afirma que a área é considerada uma práxis móvel ${ }^{2}$ e suas investigações estão sempre mudando. Kramsch (2017, p. 215), mais recentemente, afirma que a Linguística Aplicada se concentra no estudo da(s) linguagem(s) e na “intrínseca relação entre linguagem, discurso, conhecimento e poder". Partimos desses meandros da Linguística Aplicada para desenhar um projeto com foco na memória e na pós-memória, envolvendo também história, educação e formação de professores de línguas, mais especificamente.

Como parte da área de Linguística Aplicada, a formação de professores de línguas tem mudado ao longo do tempo de acordo com as chamadas "viradas", ou seja, houve uma "virada comunicativa" no ensino de línguas durante a década de 1980, uma "virada reflexiva" na pesquisa na formação de professores durante os anos 1990 e uma "virada crítica", tanto na pesquisa quanto no ensino, no início dos anos 2000. Essas chamadas "viradas" são representações metafóricas dos principais interesses de tais áreas, mas uma "virada" anterior não desaparece necessariamente com o surgimento de outra posterior.

\footnotetext{
${ }^{2}$ No original: moving práxis (PENNYCOOK, 2001). Tradução nossa, assim como em todos os demais trechos traduzidos a partir de textos em inglês no restante deste trabalho.
} 
Pelo contrário, elas existem simultaneamente, influenciando a Linguística Aplicada de várias maneiras ao mesmo tempo. Nesse cenário, também ocorreu uma "virada afetiva" na área de Linguística Aplicada, envolvendo não só a aprendizagem de línguas (a visão dos alunos), como também o ensino de línguas (a visão dos professores).

Neste trabalho buscamos combinar a "virada afetiva" e a "virada crítica". Nesse sentido, o que é considerado "afetivo" na pesquisa e na prática em Linguística Aplicada são questões que envolvem, por exemplo, as crenças dos alunos e dos professores (KALAJA et al, 2008) e/ou suas atitudes (WOODS, 1996), o conhecimento subjetivo dos professores sobre sua profissão (FREEMAN, 1996), e memórias de alunos (PAIVA, 2005; 2008) e professores (CAETANO; MATTOS, 2017) ao aprender e/ou ensinar, bem como suas experiências e histórias de vida (CORACINI, 2007). Em termos da perspectiva crítica na Linguística Aplicada, Luke (2004, p. 21) afirma que "o que tem sido considerado crítico nos últimos anos focaliza como as pessoas usam textos e discursos para construir e negociar identidade, poder e capital”. A Linguística Aplicada Crítica, portanto, como vimos, enfoca especialmente as questões de poder entrelaçadas com a linguagem, com os discursos e com a identidade. Todos esses elementos são cruciais para o foco deste estudo, justapondo, assim, a virada afetiva e a virada crítica.

Para Araújo e seus coautores $(2018$, p. 8), “poucas coisas são tão particularmente afetivas quanto as memórias de um indivíduo, de um povo ou grupo. [...] Dessa forma, memória e língua fazem parte, por assim dizer, de um bem imaterial imensurável". Nesse sentido, é possível entender por que a memória se tornou um conceito primordial na área de Linguística Aplicada. Portanto, este artigo trata das memórias e pós-memórias que os professores em serviço possam ter em relação à Ditadura no Brasil e, ao mesmo tempo, tenta criar nos participantes um sentimento de resistência para que os horrores da ditadura não voltem a se repetir.

\section{MEMÓRIA, PÓS-MEMÓRIA E IDENTIDADE}

Halbwachs (2006), em A Memória Coletiva, discorre detalhadamente sobre a formação das memórias individuais e sociais do ser humano. Para o autor, cada indivíduo carrega uma memória pessoal de suas próprias experiências e uma memória social, construída coletivamente pelo simples fato de vivermos em sociedade. Em outras palavras, uma memória interna ou autobiográfica e uma memória externa ou histórica.

Portanto, ao fazermos parte de um grupo social, formamos nossas memórias coletivas. Parte dessa memória coletiva ou social é o legado dos costumes e das tradições de um grupo. A memória coletiva de uma comunidade, contendo seus legados e tradições, 
é passada de geração em geração, por meio do contato com os mais velhos, de histórias e narrativas da família e de outras pessoas pertencentes ao grupo, e conta com o papel fundamental da escola, que sistematiza tais narrativas em forma de conhecimento histórico. É na escola que as crianças aprendem e constroem o conhecimento histórico do mundo que as cerca, do bairro, da cidade, do país e do planeta. Além disso, Halbwachs (2006, p. 84) nos lembra que "a criança também está em contato com seus avós, e através deles remonta a um passado ainda mais remoto".

Podemos dizer que esse "passado ainda mais remoto", repassado às crianças pelos avós e pelas gerações anteriores, está relacionado ao que Hirsch (2008) denominou pós-memória. Conforme ela afirma, "a pós-memória descreve a relação da segunda geração com experiências poderosas, muitas vezes traumáticas, que antecederam seu nascimento, mas foram transmitidas a eles tão profundamente que parecem constituir memórias por direito próprio" (HIRSCH, 2008, p. 103). A pós-memória, portanto, é formada indiretamente por eventos traumáticos, que aconteceram no passado, porém ainda produzem efeitos no presente. Mattos e Caetano (2019) explicam que

o termo (...) atualmente está sendo usado em várias disciplinas para entender as influências da memória em nossa identidade e como ela pode moldar nossa vida e nossos modos de ver e estar no mundo, tanto quanto como nos posicionamos e nos articulamos, ou entendemos nosso lugar e papel na sociedade (MATTOS; CAETANO, 2019, p. 178).

Um dos possíveis efeitos produzidos pelos eventos traumáticos e pelas histórias que ouvimos sobre eles são nossas identidades pessoais e profissionais, que começam a se formar desde muito cedo. Aditchie (2009, n. p.) nos lembra "quão impressionáveis e vulneráveis somos diante de uma história, principalmente quando crianças”. Ouvindo histórias culturais e familiares do passado, crescemos aprendendo-as e formando nossas identidades ao mesmo tempo em que somos formados por elas.

Coracini (2007, p. 9) entende a identidade como formada por interdiscursos, que são "fragmentos de múltiplos discursos que constituem a memória discursiva" do ser humano, recebidos como herança e continuamente modificados e transformados. Isso ocorre justamente em nossas relações com o outro, numa rede imbricada de interrelações, ao mesmo tempo constituída e constitutiva de nossos valores, nossas crenças, nossas ideologias e nossas culturas. Segundo a autora, esses interdiscursos, ou memória discursiva, constituem inúmeras vozes que formam nossa visão de mundo e, dialeticamente, também são formados por ela. Memória e pós-memória, dessa forma, parecem estar interligadas 
por nossas experiências de vida e nossas relações com o outro. Para Almeida (2017, p. 10), "a memória é situada num verdadeiro conflito entre o lembrar e o esquecer".

\section{Pós-Memória e Formação Crítica de Professores de Línguas}

A formação crítica de professores de línguas é um termo relativamente novo que está sendo usado para descrever abordagens críticas para o desenvolvimento de professores de línguas tanto em pré-serviço quanto em serviço ${ }^{3}$, em contraste com as visões mais tradicionais com foco no treinamento e na neutralidade. Se estamos promovendo uma perspectiva crítica no ensino de línguas, os professores devem estar preparados para usar visões críticas nas salas de aula (FERRAZ, 2015; MATTOS, 2014; MONTE MÓR, 2015). Ferraz (2015, p. 89) explica que "uma educação exclusivamente mecanicista/neoliberal já não comporta mais as transformações as quais estamos vivendo". Ele afirma, assim, que precisamos agora de uma educação que tenha como foco a consciência política, a criticidade e a cidadania.

Recorremos a Monte-Mór (2013, p. 127), que, ao discutir a agência docente, questiona: "é possível que a explicação para o resultado educacional insatisfatório para a cidadania crítica e agência no Brasil - retratada por pesquisas acadêmicas - se deve à história da construção identitária do professor e cidadão brasileiro?". Para tentar responder à sua própria pergunta, a autora afirma que três grandes influências históricas na educação brasileira já foram identificadas: "a perspectiva missionária Jesuíta; o colonialismo que chegou junto com os Jesuítas e outros que vieram mais tarde e ficaram mais tempo; e as visões autoritárias vividas durante a ditadura (1964-1985)" (MONTE-MÓR, 2013, p. 127). Em síntese, ela diz em tom de brincadeira que "as almas dos professores brasileiros são habitadas por um Jesuíta, um colonizador e um autoritário" (idem) e, por isso, essas três influências podem ter impactado a construção da identidade dos professores brasileiros.

As imagens da Figura 1 são uma tentativa de representar essas três influências que, segundo Monte-Mór (2013), ainda hoje, habitam as identidades dos professores brasileiros. Da esquerda para a direita, no sentido horário, temos o professor Jesuíta que, nesse caso, seria aquele "iluminado" pelos saberes que possui e, consequentemente, responsável por transmitir esse saber, iluminando, também, seus alunos; o professor colonizador, responsável por trazer, para a sala de aula, uma verdade absoluta que os alunos devem aprender sem contestar; e por fim, o professor autoritário, um ser dominante,

\footnotetext{
${ }^{3}$ Embora o termo esteja sendo usado tanto para formação de professores em pré-serviço quanto em serviço, neste trabalho todos os participantes já são professores em serviço, conforme veremos adiante.
} 
um ditador, que domina seus alunos e, se necessário, até os tortura (por meio da utilização de castigos), como ocorreu no período militar brasileiro.

Figura 1: Colagem de imagens que representam as influências na identidade de professores brasileiros: um Jesuíta, um colonizador e um autoritário (Conf. Monte-Mór, 2013).
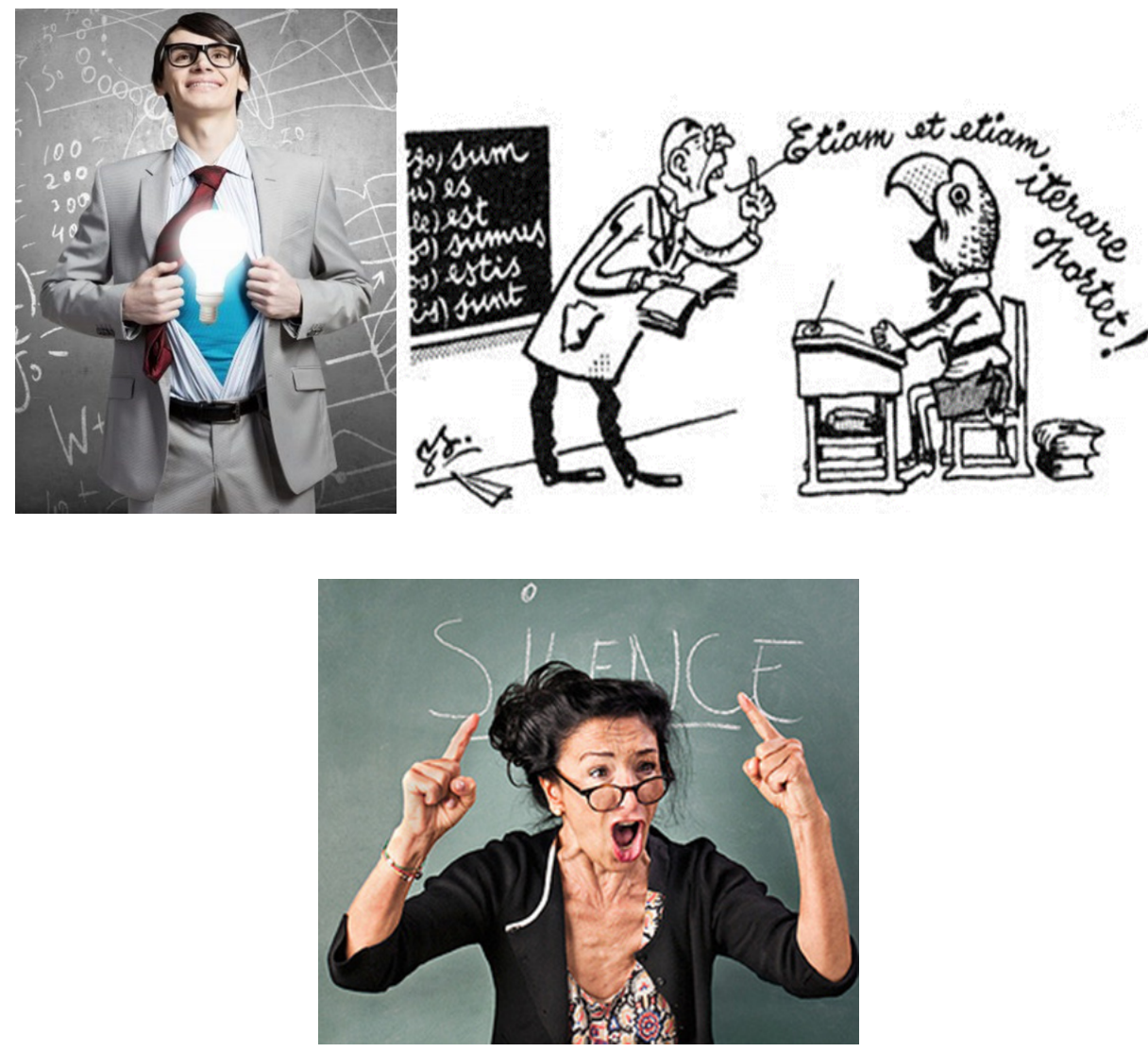

Fontes: as imagens estão disponíveis respectivamente em: https://kognity.com/blog/whatmakes-a-modern-teacher/; http://estudiomuchoeducacion.blogspot.com/2011/07/modelosdidacticos.html; https://educacaoecnv.wordpress.com/2018/04/17/vamos-falar-de-autoridade/. Acesso: 22/08/2017.

Giroux (2005) defende que a educação deve assumir o papel de prática crítica, ou "práxis", conforme já havia sido proposto por Paulo Freire (1997) em relação à pedagogia. Dessa forma, tal prática crítica seria capaz de

fornecer os meios para desconectar a aprendizagem do senso comum do impacto puramente ideológico da mídia de massa, das tendências regressivas associadas à hipermasculinidade, dos rituais da violência diária, da inabilidade de se identificar com os outros, assim como 
das ideologias de repressão do estado e suas ilusões de império (GIROUX, 2005, p. 235).

Segundo o autor, "a autorreflexão e o desejo de resistir às forças materiais e simbólicas de dominação são centrais para um modelo de educação que se recusa a repetir os horrores do passado e se engaja nas possibilidades do futuro" (idem). No estudo aqui relatado, nosso principal objetivo foi justamente abrir espaço para que os professores participantes refletissem sobre as histórias que conheceram de violência, tortura e assassinato relacionadas ao longo período de dominação política durante a Ditadura Militar no Brasil e reimaginar possibilidades para resistência a eventos semelhantes que podem acontecer no futuro.

\section{CONTEXTO E METODOLOGIA DA PESQUISA}

O contexto de pesquisa para o estudo aqui relatado foi um curso de especialização em ensino de inglês em uma grande universidade pública brasileira. Os participantes do estudo eram todos professores em serviço que estavam matriculados no curso e, em sua grande maioria, atuavam em contexto de escolas particulares e/ou cursos especializados em ensino de inglês. O conteúdo do curso foi, em geral, focado em metodologias de ensino, especialmente a partir de uma perspectiva crítica, introduzindo novas abordagens para o ensino de línguas, como o Letramento Crítico e os Multiletramentos.

Buscando promover uma atitude reflexiva nos professores-alunos, o curso não envolveu nenhum teste ou quaisquer outras formas de avaliação somativa. Ao contrário, a avaliação foi baseada em seminários de discussão, que tinham por objetivo ajudar os professores a aprender uns com os outros e a repensar seus próprios pontos de vista, seus valores e suas crenças. Durante o curso, um dos temas dos seminários foram as memórias da Ditadura Militar no Brasil e como os professores de línguas podem usar a História do país para conscientizar seus próprios alunos e ajudá-los a resistir a velhas e novas formas de imposição de poder e violência. Ao final do curso, os professoresalunos realizaram uma atividade reflexiva final, como parte do sistema de avaliação da disciplina. A atividade reflexiva consistiu de três questões opcionais sobre as possíveis contribuições do curso para a vida pessoal e profissional dos participantes, sobre como o curso poderia contribuir para mudanças futuras no contexto social dos participantes e, por fim, sobre suas memórias e histórias relacionadas ao período militar brasileiro.

Assim, os dados foram gerados a partir das narrativas escritas sobre as experiências dos participantes, que foram produzidas como respostas à atividade 
reflexiva final. No total, eram 32 professores-alunos matriculados no curso, mas, como as questões da atividade reflexiva eram opcionais, ou seja, eles podiam escolher qual delas gostariam de responder, apenas nove participantes responderam à questão sobre o período militar brasileiro. ${ }^{4}$

Naturalmente, a produção reflexiva dos participantes foi caracterizada por narrativas em primeira pessoa, como veremos na análise apresentada na próxima seção. Segundo Bruner (2002), narrativas e histórias são uma forma de pensar, uma maneira de organizar a experiência humana. Além disso, para Schaafsma e Vinz (2011, p. 1), "as narrativas têm o potencial de fornecer explicações complexas" das experiências humanas. Nesse contexto, interessou-nos particularmente "os detalhes, complexidades, contextos e histórias" (idem) dos professores participantes, que poderiam revelar experiências e memórias relacionadas à Ditadura Militar.

Na próxima seção, relatamos os resultados de um tipo de pesquisa que se enquadra no paradigma qualitativo e se caracteriza também como pesquisa narrativa na área de formação de professores. Neste trabalho, por questões de espaço, discutiremos somente cinco das narrativas dos participantes. ${ }^{5}$

\section{PÓS-MEMÓRIA COMO RESISTÊNCIA}

Para a análise que aqui apresentaremos, as narrativas geradas na atividade reflexiva final foram numeradas de N1 a N5, a fim de preservar a identidade dos participantes da pesquisa. Algumas das narrativas discutidas nesta seção foram analisadas sob diferentes temas e, por esse motivo, podem ser discutidas mais de uma vez. As narrativas foram escritas originalmente em inglês ${ }^{6}$ e foram traduzidas para este trabalho. Alguns dos trechos das narrativas foram destacados em negrito para deixar mais claro ao leitor o tema específico a que nos referimos.

Como veremos nos excertos apresentados e discutidos nesta seção, os participantes da pesquisa debateram diversos temas em suas narrativas. Alguns relataram histórias de família que falavam de parentes que sofreram durante o período militar. Outros, embora não tenham vivido o período da ditadura militar, acreditam que, ainda assim, sofreram

\footnotetext{
${ }^{4}$ Por se tratar de pesquisa envolvendo seres humanos, o projeto original foi submetido à análise do Comitê de Ética em Pesquisa (COEP), e foi aprovado em 23/08/2018 sob o número CAAE: 95164418.0.0000.5149.

${ }^{5}$ Para maiores detalhes e outros resultados relevantes deste trabalho, ver Mattos e Coura (2021b). ${ }^{6}$ Apresentaremos as narrativas em português no corpo do texto e o excerto original correspondente em nota de rodapé. Os excertos originais foram modificados apenas minimamente para não causar dificuldade de compreensão ao leitor.
} 
com suas influências. Os relatos falam de efeitos na educação, repressão e silenciamento, artefatos e práticas escolares relacionadas à Ditadura Militar brasileira, bem como lições que se estendem para além dos dias atuais. Sendo assim, as narrativas dos participantes, como veremos, falam do passado, do presente e do futuro, como uma forma de resistência para que as atrocidades do passado não se repitam.

Para começar, apresentamos, a seguir, o primeiro excerto de uma das narrativas, que foi enumerada como N1. A narrativa desse participante mostra que, na educação, ainda existem muitas influências da Ditadura Militar, como a censura de determinados conteúdos na sala de aula e o silenciamento dos alunos:

N1: Embora eu tenha nascido no final da ditadura brasileira, minha família foi muito influenciada por ela (...) ouvi muitas histórias sobre censura e mesmo não tendo sido pessoalmente afetada por isso, sei que minha formação foi um reflexo daqueles dias sombrios. (...) Assuntos polêmicos não faziam parte das aulas, e os alunos não tinham muita voz. ${ }^{7}$

Como percebemos no excerto acima, essa participante nasceu após o fim da Ditadura Militar. As memórias que ela traz das histórias foram contadas por seus pais. Por mais que ela própria nunca tenha vivido a ditadura, as histórias que conta podem nos lembrar da professora ditadora, que proíbe a discussão de certos assuntos em sala de aula e sempre cala os alunos.

O excerto seguinte também pertence a uma participante que não vivenciou a Ditadura:

N2: A única história que tenho da Ditadura Militar Brasileira é, na verdade, a história da minha vida e porque me tornei a pessoa que sou hoje. Isso remonta à versão da história que conheço sobre meu avô. ${ }^{8}$

Essa participante afirma que não viveu durante a Ditadura Militar. No entanto, as narrativas ou histórias contadas por sua família sobre seu avô naquela época fazem

\footnotetext{
${ }^{7}$ No original: N1: Although I was born at the end of Brazilian Dictatorship, my family was very influenced by that (...) I heard lots of stories about censorship and even though I wasn't personally affected by that, I know that my education was a reflection of those dark days. (...) Controversial items were not part of the class, and students didn't have much voice.

${ }^{8}$ No original: N2: The only related story I have of the Brazilian Military Dictatorship is actually the story of my life, and why I became the person who I am today. It goes back to the version of the story I know about my grandfather.
} 
parte de sua identidade. Ela também fala sobre como certos artefatos ajudam as pessoas a preservar as memórias do passado:

N2: Eu cresci lendo os livros do meu avô e suas anotações sobre o conteúdo. (...) Tínhamos também uma placa de rua, de uma rua real da nossa cidade, que carrega o nosso sobrenome e também tinha um prédio na cidade em homenagem ao meu avô. ${ }^{9}$

Nesse excerto, vemos como artefatos, como livros, uma placa de rua e até mesmo um prédio, podem desencadear memórias do passado. Outros artefatos, por exemplo, prédios e ruas com nomes de figuras influentes do período militar, podem ajudar a preservar a história que a Ditadura tentou silenciar e apagar.

Outro participante também falou sobre o silenciamento. Ele mencionou como funcionava a censura durante o período militar. Segundo ele, agentes do governo ouviam músicas e assistiam a filmes com antecedência, a fim de julgar se deveriam ser censurados ou não. No excerto abaixo, este participante se refere a como as pessoas tentaram escapar da censura:

N3: Quando as pessoas, especialmente os músicos, criticavam a ditadura, era através de músicas cujas letras eram ambíguas para não serem censuradas. ${ }^{10}$

Além de falar de histórias do passado que herdaram de seus pais e avós, alguns participantes falaram sobre o presente e como a discussão sobre a pós-memória e o governo militar no Brasil ainda tem adeptos:

N4: Felizmente, eu não passei por aquele período horrendo da nossa história, mas me assusta ver muitas pessoas reivindicando a volta dos militares ao poder, o que evidencia o puro desconhecimento, por parte da população, de nossas mais tristes lembranças. (...) [isso]

\footnotetext{
${ }^{9}$ No original: N2: I grew up reading my grandfather's books and his notes about the content. (...) We also had a street sign, from a real street in our city, that carries our last name and there was also a building in the city in honor of my grandfather.

${ }^{10}$ No original: N3: When people, mainly the musicians, got to criticize the Dictatorship, it was through songs whose lyrics were disguised so as not to be censored.
} 
sintetiza a importância de nossas memórias passadas na construção de nossas identidades como cidadãos e pessoas. ${ }^{11}$

Nessa narrativa, mais uma vez, vemos que essa participante é muito jovem para ter vivido a ditadura. Ela a chama de "período horrível da nossa História" devido às inúmeras atrocidades cometidas pelo governo e pelos governantes, como violência, tortura e até assassinato. Nesse excerto, há uma espécie de reclamação sobre a falta de trabalho acerca da memória no Brasil e a importância desse tema para a construção da identidade e, consequentemente, para o exercício da cidadania.

O último excerto das narrativas dos participantes que vamos discutir neste artigo fala sobre o futuro. A participante também nasceu após o fim da Ditadura Militar e, em sua narrativa, afirma não conhecer histórias desse período. Todavia, por meio das discussões que tivemos em aula durante o curso, parece que ela aprendeu algo:

N5: O meu pensamento crítico não foi incentivado para entender que eu deveria ter questionado essas atitudes, nem o dos meus pais. Como educadora, espero poder trazer alguma consciência para alguém de agora em diante. ${ }^{12}$

Como podemos ver, essa participante reconhece a necessidade de não permitir que seus alunos parem de pensar criticamente sobre as atrocidades do passado. Embora ela diga que, em sua experiência, não aprendeu a ser crítica em relação ao poder e à violência, parece que, de agora em diante, como profissional, ela quer ajudar a preservar as memórias do passado, trazendo consciência para seus alunos.

Muitos dos participantes deste estudo, na época da geração dos dados, ainda eram muito jovens para ter memórias próprias relacionadas à Ditadura Militar. No entanto, eles se lembraram de histórias contadas por suas gerações anteriores que poderiam ajudá-los a repensar atitudes de resistência.

Mattos e Caetano (2018), com razão, nos lembram que

\footnotetext{
${ }^{11}$ No original: N4: Fortunately, I didn't go through that horrendous period of our History, but it frightens me to see many people claiming for the return of Military to power, which evidences the sheer ignorance of part of the population of our saddest memories. (...) [it] epitomises the importance of our past memories in the construction of our identities as citizens and people.

${ }^{12}$ No original: N5: I have not been taught critical thinking to understand that I should have questioned those attitudes, but neither were my parents. Hope I can bring some awareness to someone as an educator from now on.
} 
[a] compreensão do conceito de pós-memória pode nos ajudar a perceber o papel e a importância dos professores, incluindo professores de línguas, na criação de estratégias pedagógicas capazes de produzir identidades, relações sociais e valores que possam levar a menos injustiças e abrir caminho para a prevenção de que episódios históricos traumáticos como o Holocausto e as ditaduras militares voltem a acontecer (Mattos; Caetano, 2018, p. 250).

Em nossa opinião, a formação crítica do professor de línguas pode ter um papel muito importante em ajudar os professores a se tornarem críticos em relação a várias questões, incluindo questões locais como a Ditadura brasileira, para que eles também se tornem capazes de introduzir tais discussões em suas próprias salas de aula.

As narrativas discutidas acima mostram várias instâncias de construção das identidades desses participantes. É possível analisar a influência das histórias que eles ouviram de seus pais e familiares, do que eles vivenciaram na escola e as expectativas para o futuro em termos de seu próprio desenvolvimento como professores e como eles podem contribuir para ajudar a promover as perspectivas críticas de seus alunos. Na seção final deste artigo, gostaríamos de apresentar algumas reflexões que podem ser úteis para pesquisas futuras na área de memória e formação crítica de professores de línguas.

\section{CONSIDERAÇÕES FINAIS}

Segundo Sachs (1993), uma das formas possíveis de sustentabilidade é a sustentabilidade política, ou seja, o processo de construção da cidadania para garantir a plena participação dos indivíduos nos processos de desenvolvimento da nação. Com essa definição em mente, a relevância da memória e da pós-memória para a educação é colocada em evidência e apresenta perspectiva de avanços, considerando que, segundo Mattos e Caetano (2019, p. 169), "a construção da identidade é altamente influenciada pela natureza histórica dos discursos e das ideologias que permeiam a sociedade brasileira".

Como vimos, a "virada" afetiva na Linguística Aplicada trouxe para o nosso campo mais um tema como possibilidade de pesquisa na área: a memória. Na tentativa de conciliar a "virada" afetiva com a "virada" crítica, recorremos ao conceito de pós-memória (HIRSCH, 1997; 2008), a fim de criar espaços para os professores participantes refletirem sobre seus valores, suas crenças e suas atitudes e reimaginar novas possibilidades para o futuro. Chamberlin (2006, p. 32) acredita que "memória e imaginação estão localizadas na mesma parte da alma, pois ambas nos permitem ver e ouvir algo que não está presente". Esperamos que os professores participantes desta pesquisa tenham encontrado formas 
de entrelaçar suas memórias e sua imaginação, reavaliando o passado e reconcebendo o futuro. Esperamos, também, que as narrativas aqui discutidas possam inspirar outros professores e pesquisadores, no Brasil e em outros lugares, a desenvolver projetos semelhantes de ensino e pesquisa.

Jorge e Ribeiro (2013), na introdução de um número especial da Revista Abril com foco na memória, trazem uma reflexão importante sobre o tema:

[1]embrar é um ato de recuperação e de reavaliação, que pressupõe a possibilidade de interlocução crítica com o passado. Lembramos para não esquecer; como indivíduos e como sociedade, ainda que o esquecimento seja a outra face da moeda a que chamamos memória. Lembramos para não errar de novo, para impedir que a opressão e a violência tornem a se manifestar de forma avassaladora e insidiosa (JORGE; RIBEIRO, 2013, p. 12).

Se concordamos com o que Jorge e Ribeiro afirmam na citação acima, precisamos encontrar formas de manter vivas as memórias do passado, com o intuito de que possamos resistir à opressão e à violência. As próximas gerações devem ser informadas de nossos eventos traumáticos e violentos do passado a fim de serem capazes de criar estratégias de resistência a possíveis eventos semelhantes que possam acontecer no futuro. Do nosso ponto de vista, narrativas e histórias passadas de uma geração para outra podem criar um vínculo entre o presente e o passado e, assim, abrir caminhos para um futuro melhor.

Gostaríamos de terminar este artigo citando, mais uma vez, Mattos e Caetano (2019), quando as autoras afirmam que

[r]econhecer a conexão entre [certas] condutas e o conceito de pósmemória pode levar a novas perspectivas sobre a formação de professores de línguas e sobre o papel da identidade docente na Educação Crítica de Língua Estrangeira - perspectivas que podem nos ajudar, tanto na educação quanto no ensino de línguas, a nunca esquecer as atrocidades cometidas durante a Ditadura Militar, nunca silenciar novamente, e nunca deixar que se repitam (Mattos; Caetano, 2019, p. 183).

Precisamos nos lembrar! Como diz o lema oficial do Quebec, uma das províncias do Canadá, na Figura 2: Je me souviens, que se traduz, literalmente, como "eu me lembro". Vivemos em "tempos sombrios" (Giroux, 2005). É fundamental reconhecer a importância da memória para as várias culturas do mundo e para a constituição da identidade das novas gerações. 
Figura 2: Citadelle de Québec, Québec, Canadá - Julho/2014.

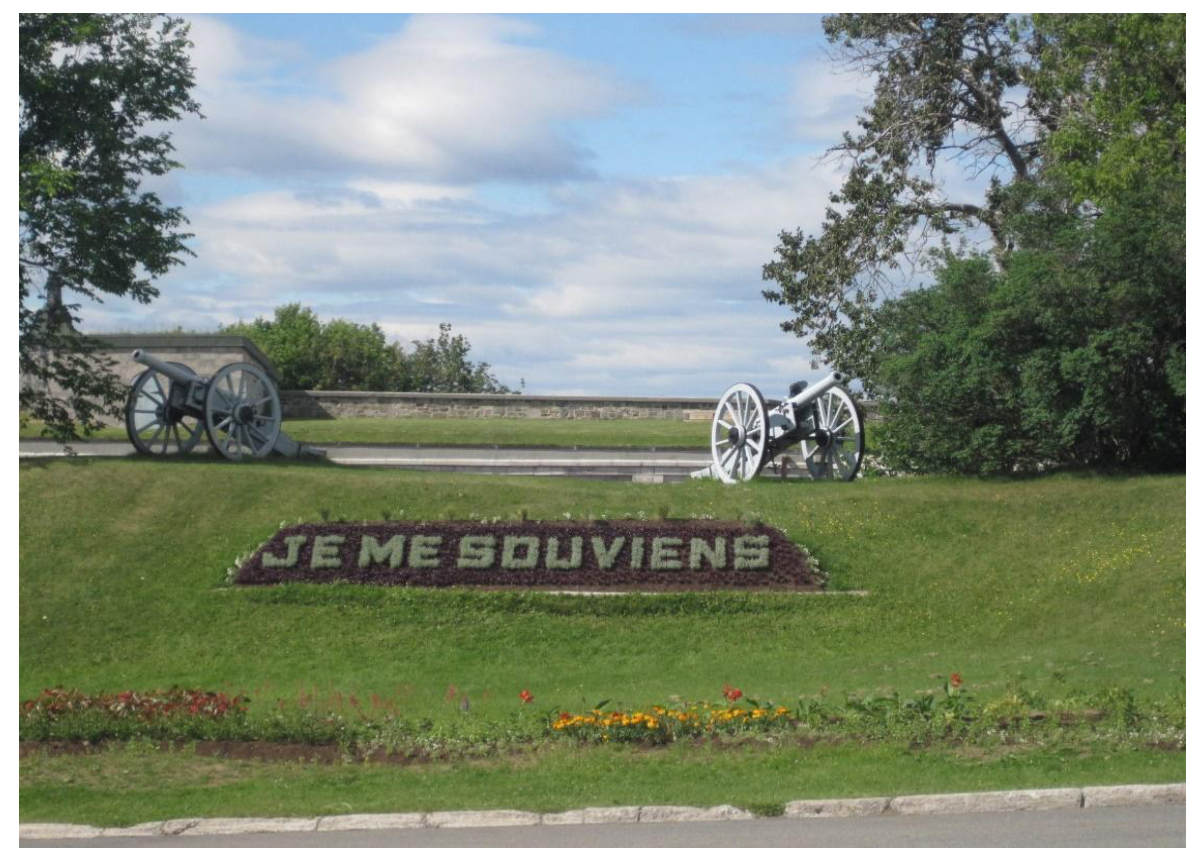

Fonte: Acervo pessoal da segunda autora.

\section{REFERÊNCIAS}

ADICHIE, C. O Perigo de uma Única História. TED Talk de Chimamanda Ngozi Adichie. Tradução de Erika Rodrigues. [S.l.: s. n.], 2009. 1 vídeo (20 min.). Disponível em: http:// www.youtube.com/watch?v=D9Ihs241zeg. Acesso em: 21 out. 2009.

ALMEIDA, J. A. Memória, Universidade, Cidadania e Constituição na Era das Comissões da Verdade: Elucubrações Comparativas a partir da Vida e Obra da Família Kucinski. In: SIMPÓSIO NACIONAL DE HISTÓRIA - Contra os Preconceitos: História e Democracia, 29., 2017, Brasília. Anais do XXIX Simpósio Nacional de História - Contra os Preconceitos: História e Democracia. Disponível em: http://www. snh2017.anpuh.org/resources/anais/54/1489624814_ARQUIVO_STANPUH2017.pdf. Acesso em: 16 set. 2017.

ARAÚJO, E. L. et al. Patrimônio Cultural e Memória Literária: Um Diálogo Ítalobrasileiro com Giorgio de Marchis. Revista Palimpsesto, ano 17, n. 27, p. 8-15, 2018. DOI: $10.12957 /$ palimpsesto.2018.38396. 
BRUNER, J. Making Stories: Law, Literature, Life. Cambridge, Mass: Harvard University Press, 2002.

CAETANO, E.; MATTOS, A. M. A. Senses in Language Teacher Education: The Power of Narratives. In: OLIVEIRA, A. L. A. M.; BRAGA, J. C. F. (ed.). Inspiring Insights from an English Teaching Scene. Belo Horizonte: FALE/UFMG, 2017. p. 26-46

CHAMBERLIN, J. E. Living Language and Dead Reckoning: Navigating Oral and Written Traditions. Vancouver: Ronsdale Press, 2006.

CORACINI, M. J. A Celebração do Outro: Arquivo, Memória e Identidade. São Paulo/ Campinas: Mercado de Letras, 2007.

FERRAZ, D. M. Educação Crítica em Língua Inglesa: Neoliberalismo, Globalização e Novos Letramentos. Curitiba: CRV, 2015.

FREEMAN, D. Redefining the Relationship between Research and What Teachers Know. In: BAILEY, K.; NUNAN, D. Voices from the Language Classroom. New York: Cambridge University Press, 1996. p. 88-115.

FREIRE, P. Pedagogia da Autonomia. 6. ed. Rio de Janeiro: Paz e Terra, 1997.

GIROUX, H. A. Border Crossings: Cultural Workers and the Politics of Education. 2. ed. New York: Routeledge, 2005.

HAlBWACHS, M. A Memória Coletiva. Tradução de Beatriz Sidou. São Paulo: Centauro, 2006.

HIRSCH, M. Family Frames: Photography, Narrative and Postmemory. Cambridge, Mass: Harvard University Press, 1997.

HIRSCH, M. The Generation of Postmemory. Poetics Today, v. 29, n. 1, p. 103-128, 2008. Disponível em: http://poeticstoday.dukejournals.org/content/29/1/103.full.pdf + html. Acesso em: 28 set. 2019.

JORGE, S. R.; RIBEIRO, M. C. Apresentação. Revista Abril, v. 5, n. 11, p. 9-12, 2013. Disponível em: http://www.revistaabril.uff.br/index.php/revistaabril/article/view/41/35. Acesso em: 28 set. 2019.

KALAJA, P.; MENEZES, V.; BARCELOS, A. M. F. (ed.). Narratives of Learning and Teaching EFL. Basingstoke, UK: Palgrave/MacMillan, 2008. 
KRAMSCH, C. Foreword. Revista Brasileira de Linguística Aplicada, Belo Horizonte, v. 17, n. 2, p. 215-217, 2017.

LUKE, A. Two Takes on the Critical. In: NORTON, B.; TOOHEY, K. (ed.). Critical Pedagogies and Language Learning. New York: Cambridge University Press, 2004. p. 21-29.

MATTOS, A. M. A. Educating Language Teachers for Social Justice Teaching. Interfaces Brasil/Canadá, v. 14, n. 2, p. 125-151, 2014. Disponível em: https://periodicos.ufpel. edu.br/ojs2/index.php/interfaces/article/view/6738/4644. Acesso em: 6 jan. 2015.

MATTOS, A. M. A; CAETANO, E. A. Memory, Postmemory and Critical Language Teacher Education. Analecta Política, v. 8, n. 2, p. 235-254, 2018. D.O.I.: 10.18566/ apolit.v8n15.a04.

MATTOS, A. M. A; CAETANO, E. A. Memória, Pós-memória e Formação Crítica de Professores de Línguas. Línguas \& Letras, v. 20, n. 46, p. 167-186, 2019. D.O.I.: http:// dx.doi.org/10.5935/1981-4755.20190010.

MATTOS, A. M. A.; COURA, M. A. Critical Language Teacher Education: Postmemory as Resistance. In: CONFERENCE ON MULTICULTURAL DISCOURSES, 7., 2020, Cluj-Napoca, Romania. Procedings of the VII Conference on Multicultural Discourses. Cluj-Napoca: Babes-Bolyai University, 2021a.

MATTOS, A. M. A.; COURA, M. A. História, Memória e Pós-memória: presente, passado e futuro na formação crítica de professores de inglês. In: CAETANO, E. A. (Org.). Pósmemória e decolonialidade no ensino de línguas no Brasil: as origens do status quo. São Carlos: Pedro \& João, 2021b. p. 179-221.

MONTE MÓR, W. The Development of Agency in a New Literacies Proposal for Teacher Education in Brazil. In: JUNQUEIRA, E. S.; BUZATO, M. K. (ed.). New Literacies, New Agencies? A Brazilian Perspective on Mindsets, Digital Practices and Tools for Social Action in and out of School. Pieterlen, Switzerland: Peter Lang, 2013. p. 126-146.

MONTE MÓR, W. Learning by Design: Reconstructing Knowledge Processes in Teaching and Learning Practices. In: COPE, B.; KALANTZIS, M. (ed.). A Pedagogy of Multiliteracies: Learning by Design. New York: Palgrave Macmillan, 2015. p. 186-209.

PAIVA, V. L. M. O. Autonomia e complexidade: uma análise de narrativas de aprendizagem. In: FREIRE, M. M.; ABRAHÃO, M. H. V.; BARCELOS, A. M. F. (org.). Linguística Aplicada e Contemporaneidade. Campinas/São Paulo: Pontes/ALAB, 2005. p. 135153. 
PAIVA, V. L. M. O. Multimedia Language Learning Histories. In: KALAJA, P.; MENEZES, V.; BARCELOS, A. M. (org.). Narratives of Learning and Teaching EFL. London: Palgrave MacMillan, 2008. p. 199-213.

PENNYCOOK, A. Critical Applied Linguistics: A Critical Introduction. New Jersey/ London: Lawrence Erlbaum Associates, 2001.

SACHS, I. Estratégias de Transição para do século XXI: Desenvolvimento e Meio Ambiente. São Paulo: Studio Nobel/Fundação para o Desenvolvimento Administrativo, 1993.

SCHAAFSMA, D.; VINZ, R. On Narrative Inquiry: Approaches to Language and Literacy Research. New York/London: Teachers College Press/Columbia University, 2011.

WOODS, D. Teacher Cognition in Language Teaching: Beliefs, Decision-making and Classroom Practice. Cambridge: Cambridge University Press, 1996.

Recebido em: 31 jul. 2021. Aceito em: 22 set. 2021. 